\title{
Inclusão social, educação inclusiva e educação especial: enlaces e desenlaces
}

Com este editorial objetiva-se estabelecer diferenças, pontos e contrapontos entre inclusão social, educação inclusiva e educação especial. O conceito de inclusão vem sendo amplamente e demasiadamente mal compreendido segundo a interpretação do senso comum. Esta crítica diz respeito ao fato de o mesmo ser "aplicado" apenas aos estudantes, público-alvo da educação especial, e ao contexto educacional. É frequente a manifestação pública de expressões equivocadas como: "aluno de inclusão" e "sala de inclusão".

A inclusão é um paradigma que se aplica aos mais variados espaços físicos e simbólicos. Os grupos de pessoas, nos contextos inclusivos, têm suas características idiossincráticas reconhecidas e valorizadas. Por isto, participam efetivamente. Segundo o referido paradigma, identidade, diferença e diversidade representam vantagens sociais que favorecem o surgimento e o estabelecimento de relações de solidariedade e de colaboração. Nos contextos sociais inclusivos, tais grupos não são passivos, respondendo à sua mudança e agindo sobre ela. Assim, em relação dialética com o objeto sócio-cultural, transformam-no e são transformados por ele.

Desconstruindo a ideia de homem padrão (MACE, 1990), o conceito de Desenho Universal emerge na perpectiva inclusiva, de maneira a permitir a construção do design e da arquitetura acessíveis, sem necessidade de adaptações pontuais.

O desenho universal, que fundamenta a aplicação da Lei Brasileira de Inclusão da Pessoa com Deficiência (BRASIL, 2015) expressa bem a ideia discutida. O artigo 102 da referida lei afirma que "[...] desenho universal: concepção de produtos, ambientes, programas e serviços a serem usados por todas as pessoas, sem necessidade de adaptação ou de projeto específico, incluindo os recursos de tecnologia assistiva." (BRASIL, 2015, p. 29).

Não faz sentido, por exemplo, estudantes com deficiências participarem efetivamente apenas da educação básica. Quando concluírem o ensino médio, encontrarão espaços sociais para além dos muros escolares, prontos para a exclusão.

Inclusão, portanto, é uma prática social que se aplica no trabalho, na arquitetura, no lazer, na educação, na cultura, mas, principalmente, na atitude e no perceber das coisas, de si e do outrem.

$\mathrm{Na}$ área educacional, o trabalho com identidade, diferença e diversidade é central para a construção de metodologias, materiais e processo de comunicação que dêem conta de atender o que é comum e o que é específico entre os estudantes. 
Como afirma Mantoan (2004, p. 7-8): "há diferenças e há igualdades, e nem tudo deve ser igual nem tudo deve ser diferente, [...] é preciso que tenhamos o direito de ser diferente quando a igualdade nos descaracteriza e o direito de ser iguais quando a diferença nos inferioriza."

Há aqui outro ponto controverso, a diferença entre a educação inclusiva e a educação especial, quase sempre tomadas como sinônimas.

Uma questão de pano de fundo nos é imposta: quais são os estudantes foco da educação inclusiva? A resposta é: todos. Quer dizer, ela se estende aos alunos, público-alvo da educação especial (BRASIL, 2013a), e àqueles que não são público-alvo dessa modalidade de ensino: os alunos brancos, negros, de distintos gêneros, índios, homossexuais, heterossexuais etc. Ou seja, aos seres humanos reais, com foco prioritário aos excluídos do processo educacional. De forma contraditória, a cultura atual, principalmente a ocidental, tenta moldá-los e "formá-los" como seres homogêneos. Como consequência, os que não se enquadram nos referidos padrões e segundo as regras de normalização forjadas socialmente, recebem vários adjetivos: "anormais", "deficientes”, “incapazes", "inválidos”, etc.

A educação inclusiva constitui um paradigma educacional fundamentado na concepção de direitos humanos, que conjuga igualdade e diferença como valores indissociáveis, e que avança em relação à idéia de eqüidade formal ao contextualizar as circunstâncias históricas da produção da exclusão dentro e fora da escola. (BRASIL, 2008, p. 1).

O trabalho didático-pedagógico em sala de aula, com o comum e o específico entre a diversidade que caracteriza o ser humano, constitui o objetivo da inclusão escolar que

[...] postula uma reestruturação do sistema educacional, ou seja, uma mudança estrutural no ensino regular, cujo objetivo é fazer com que a escola se torne inclusiva, um espaço democrático e competente para trabalhar com todos os educandos, sem distinção de raça, classe, gênero ou características pessoais, baseando-se no princípio de que a diversidade deve não só ser aceita como desejada. (BRASIL, 2001, p. 40).

Em práticas educacionais formais, a aplicação do Desenho Universal leva em conta a diversidade de gênero, etnia, idade, estatura, deficiência, ritmos e estilo de aprendizagem nos projetos de ensino (BURGSTAHLER, 2009).

Aplicando o conceito de educação inclusiva ao educando, público-alvo da educação especial, temos uma relação bilateral de transformação do ambiente educacional e do referido educando, em que o primeiro gera, mobiliza e direciona as condições para a participação efetiva do segundo. Esse, por sua vez, age ativamente sobre tal transformação, modificando e sendo modificado por ela.

Por outro lado,

[...] a educação especial é uma modalidade de ensino que perpassa todos os níveis, etapas e modalidades, realiza o atendimento educacional especializado, disponibiliza os recursos e serviços e orienta quanto a sua utilização no processo de ensino e aprendizagem nas turmas comuns do ensino regular. (BRASIL, 2008, p. 7). 
A lei no 12.796, de 4 de abril de 2013, que altera a Lei nº 9.394, de 20 de dezembro de 1996, que estabelece as diretrizes e bases da educação nacional, para dispor sobre a formação dos profissionais da educação e dar outras providências (BRASIL, 2013a), determina em seu Art. 4, Incisos I e III:

Art. $4^{\circ} \mathrm{O}$ dever do Estado com educação escolar pública será efetivado mediante a garantia de:

I - educação básica obrigatória e gratuita dos 4 (quatro) aos 17 (dezessete) anos de idade, organizada da seguinte forma

a) pré-escola;

b) ensino fundamental;

c) ensino médio; [...]

III - atendimento educacional especializado gratuito aos educandos com deficiência, transtornos globais do desenvolvimento e altas habilidades ou superdotação, transversal a todos os níveis, etapas e modalidades, preferencialmente na rede regular de ensino. (BRASIL, 2013a).

Participam dessa modalidade de ensino os estudantes público-alvo da educação especial, ou seja, com deficiência (visual, auditiva, física e intelectual) (BRASIL, 2015), com transtorno global de desenvolvimento e com altas habilidades ou superdotação. Ela deve ser oferecida, preferencialmente, na rede regular de ensino e de forma complementar e/ou suplementar (BRASIL, 2008). O termo "preferencialmente" não diz respeito à educação regular e sim ao atendimento educacional especializado.

Sobre o atendimento educacional especializado presente no inciso III supracitado, em perfeito acordo com o artigo 208 da Constituição Federal do Brasil (BRASIL, 1988), se faz necessário esclarecer: (i) o artigo 208 do capítulo III - Da Educação, da Cultura e do Desporto - da Constituição prescreve que o dever do Estado com a educação será efetivado mediante a garantia de: "[...] atendimento educacional especializado aos portadores de deficiência, preferencialmente na rede regular de ensino" (MANTOAN, 2006, p. 27); (ii) o "preferencialmente" refere-se a "atendimento educacional especializado", ou seja, o que é necessariamente diferente no ensino para melhor atender às especificidades dos estudantes com deficiência, ou segundo o inciso III do artigo 3 da lei $\mathrm{n}^{\circ} 12.796$, aos alunos com deficiência, transtorno global de desenvolvimento e altas habilidades ou superdotação. (BRASIL, 2013a).

Como exemplo, temos o ensino do Braille e do Soroban para os educandos cegos e da Língua Brasileira de Sinais (LIBRAS) para os surdos, quer dizer, aquilo que é específico desses alunos, a fim de que os mesmos possam ter acesso ao currículo comum. O ensino de tais conteúdos é objeto da educação especial e deve ser ofertado, preferencialmente na rede regular de ensino, no atendimento educacional especializado, no contraturno do ensino regular do educando com deficiência, transtorno global de desenvolvimento e com altas habilidades ou superdotação. Ainda, os conteúdos do atendimento educacional especializados não devem substituir os da educação regular. Devem ser complementares, para os alunos com deficiências e transtorno global de desenvolvimento ou suplementares para os educandos com altas habilidades ou superdotação. (BRASIL, 2013b).

A estrutura proposta pelo desenho universal pressupõe a diversidade e o trabalho com identidade e diferença em sua constituição. Metodologia, processo de comunicação e material instrucional pensado sobre a estrutura referida precisam ser aplicados para toda a sala de aula, devendo ser contemplado na metodologia, processo de comunicação e material instrucional, 
elementos próprios dos princípios da diversidade, identidade e diferença, e não da homogeneidade e dos espaços homogeneizantes, esses últimos produtos de construção social.

São exemplos de materiais instrucionais pensados sob a estrutura do desenho universal, as maquetes e experimentos multissensoriais para o ensino de física de estudantes com e sem deficiência visual contidas em Camargo (2016), uma vez que esses recursos didático-pedagógicos valorizam a diversidade sensorial e discursiva nos processos de ensino, favorecendo a participação efetiva de todos em sala de aula.

Hoje, mais que a construção de políticas públicas, como o estatuto da Pessoa com Deficiência (BRASIL, 2015), a convenção sobre os direitos das pessoas com deficiência (BRASIL, 2009), a Política Nacional de Educação Especial na Perspectiva da Educação Inclusiva (BRASIL, 2008), etc., é o momento de praticá-las, para a promoção de participação efetiva de todos os seres humanos, principalmente dos excluídos dos mais variados espaços sociais.

Como afirmara Vigotski (1997, p. 77, tradução nossa), "um ponto do sistema Braille fez mais pelo cego que mil obras de caridade” E por quê? Na opinião de Vigotski, é pelo fato de Braille ter incluído tais pessoas no mundo da leitura e da escrita. A partir de 1825, quando o jovem francês Louis Braille (1809-1852) terminou o seu sistema de célula com seis pontos, os cegos puderam efetivamente ter acesso aos estudos, para que fosse possível, atualmente, consolidar esse acesso e ainda possibilitar o ingresso e a permanência no trabalho.

Isso mostra a importância da educação, em particular, da educação em física, química e biologia, para todas as pessoas, como fundamento das conquistas sociais para a promoção de cidadania de um povo, elemento este indissociável da heterogeneidade que o caracteriza. A atual crise política que assola o Brasil traz um discurso contraditório e, às vezes, confuso sobre "qualidade de ensino", que na opinião do autor do presente editorial, objetiva retirar dos educandos brasileiros, público ou não público da educação especial, os instrumentos psicológicos de mediação (VIGOTSKI, 2001) que lhes possibilitam interpretar o mundo não natural e que define conceitos como normalidade e deficiência. É preciso, a todo custo, desconstruir a "qualidade de ensino" imposta no Brasil (2016).

Eder Pires de Camargo Universidade Estadual Paulista “Júlio de Mesquita Filho" (Unesp), Faculdade de Engenharia de Ilha Solteira, Departamento de Física e Química. e-mail: <camargoep@dfq.feis.unesp.br>. 


\section{Referências}

BRASIL. Decreto $\mathbf{n}^{\circ} \mathbf{6 . 9 4 9}$, de 25 de agosto de 2009. Promulga a convenção internacional sobre os direitos das pessoas com deficiência e seu protocolo facultativo, assinados em Nova York, em 30 de março de 2007. Brasília, 2009. Disponível em: < http:/ /www. planalto.gov.br/ccivil_03/_Ato2007-2010/2009/Decreto/D6949. htm >. Acesso em: 21 fev. 2014.

Lei n. 12.976, de 4 de abril de 2013. Altera a lei no 9.394 , de 20 de dezembro de 1996, que estabelece as diretrizes e bases da educação nacional, para dispor sobre a formação dos profissionais da educação e dar outras providências. Brasília, 2013a. Disponível em: <http://www.planalto.gov.br/ccivil_03/_ato2011-2014/2013/lei/ 112796.htm>. Acesso em: 1 mar. 2014.

Lei $\mathrm{n}^{\circ}$ 13.146, de 6 de julho de 2015. Institui a lei brasileira de inclusão da pessoa com deficiência (estatuto da pessoa com deficiência). Brasília, 2015. Disponível em: <http://www. planalto.gov.br/ccivil_03/_ato2015-2018/2015/Lei/L13146.htm>. Acesso em: 16 jan. 2017.

Medida provisória $\mathrm{n}^{\mathrm{0}} \mathbf{7 4 6}$, de 22 de setembro de 2016. Institui a política de fomento à implementação de escolas de ensino médio em tempo integral, altera a lei $n^{\circ} 9.394$, de 20 de dezembro de 1996, que estabelece as diretrizes e bases da educação nacional, e a lei $n^{\circ} 11.494$ de 20 de junho 2007, que regulamenta o fundo de manutenção e desenvolvimento da educação básica e de valorização dos profissionais da educação, e dá outras providências. Brasília, 2016. Disponível em: <http://www.planalto.gov.br/ccivil_03/_ Ato2015-2018/2016/Mpv/mpv746.htm>. Acesso em: 13 jan. 2017.

BRASIL. Constituição (1988). Constituição da República

Federativa do Brasil. Brasília, 1988. Disponível em: < http://www. planalto.gov.br/ccivil_03/constituicao/constituicao.htm>. Acesso em: 25 jun. 2015.

BRASIL. Ministério da Educação. Diretrizes nacionais para a educação especial na educação básica. Brasilia, 2001. Disponível em: < http://portal.mec.gov.br/seesp/arquivos/pdf/diretrizes.pdf>. Acesso em: 16 jan. 2017.

\section{Nota técnica no 055 / 2013 / MEC / SECADI /}

DPEE. Orientação à atuação dos centros de AEE, na perspectiva da educação inclusiva. Brasília, 2013b. Disponível em: <http://www.ppd. mppr.mp.br/arquivos/File/NOTATECNICAN055CentrosdeAEE. pdf $>$. Acesso em: 30 jun. 2015.

Política nacional de educação especial na perspectiva da educação inclusiva. Brasília, 2008. Disponível em: < http:// portal.mec.gov.br/arquivos/pdf/politicaeducespecial.pdf $>$. Acesso em: 21 fev. 2014. 
BURGSTAHLER, S. Universal design in education: principles and applications. Seattle: University of Washington, 2009. Disponível em: <http://www.washington.edu/doit/sites/default/files/atoms/files/ Universal-Design-Education-Principles-Applications.pdf $>$. Acesso em: 13 jan. 2017.

CAMARGO, E. P. Inclusão e necessidade especial: compreendendo identidade e diferença por meio do ensino de física e da deficiência visual. São Paulo: Livraria da Física, 2016.

MACE, R. et al. Accessible environments: toward universal design. In: PRIESER, W. E.; VISCHER, J. C.; WHITE, E. T. (Ed.). Innovation by design. New York: Van Nostrand Reinhold, 1990. p. 187-219.

MANTOAN, M. T. E. Inclusão escolar: o que é? por quê? como fazer? São Paulo: Moderna, 2006.

O direito de ser, sendo diferente, na escola. Revista CEJ, Brasília, n. 26, p. 36-44, 2004. Disponível em: <http:/ /www.cjf.jus. br/ojs2/index.php/revcej/article/view/622>. Acesso em: 13 jan. 2017.

VIGOTSKI, L. S. A construção do pensamento e da linguagem. São Paulo: Martins Fontes, 2001.

El niño ciego. In: Fundamentos de defectología.

Havana: Editorial Pueblo y Educación, 1997. p. 74-87. (Obras escogidas, tomo V).

Endereço para contato: Departamento de Física e Química, Faculdade de Engenharia, UNESP, Avenida Brasil 56. CEP: 15385-000 Ilha Solteira, SP, Brasil. 